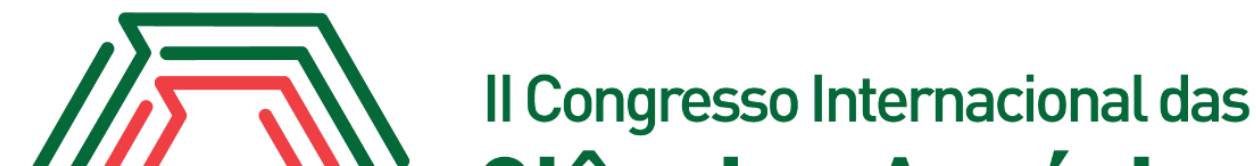 Ciências Agrárias COINTER - PDVAgro 2017
}

\section{CARACTERIZAÇÃO ANATÔMICA DE FOLHAS DA ANDIROBA (CARAPA GUIANENSIS AUBL.), PARA FINS DE DEFINÇÕES DE USO POPULAR.}

\author{
Apresentação: Pôster
}

\begin{abstract}
Beatriz Chaves da Silval ${ }^{1}$; Gabriela Nascimento Oliveira ${ }^{2}$; Denilson do Nascimento Reis Júnior ${ }^{3}$; Thiago Henrique da Silva Pantoja ${ }^{4}$; Joyce Ananda Sousa Paixão ${ }^{5}$
\end{abstract}

\section{Introdução}

A espécie Carapa guianensis Aubl., é nativa da Amazônia, sendo muito utilizada pelas populações da região Norte do Brasil, ocorre em toda a Bacia Amazônica, atingindo limites de ocorrência até o bioma Mata Atlântica, sendo encontrada no Pará até Paraíba.

Lorenzi (2000), classifica a espécie como árvores perenifólia, heliófila, de mata primária, com característica de várzea úmidas e inundáveis, no qual apresentam boa regeneração natural nas capoeiras de várzeas e produz anualmente grande quantidade de sementes viáveis.

Sua madeira é moderadamente pesada, de cor avermelhada e praticamente inatacável por cupins e empregada na fabricação de móveis, construção civil e na indústria naval e possui diversas propriedades medicinais e cosméticas.

A espécie é conhecida vulgarmente como andiroba, e o seu fruto e sementes possuem milicianos, que são compostos muito amargos que têm importante função em nosso organismo. (DELDUQUE,1999).

Estudo das estruturas secretoras baseia-se em observações morfológicas e anatômicas do exsudato por elas produzido, avaliado por meio de análises histoquímicas, neste sentido, o presente trabalho tem como objetivo caracterizar anatomicamente as folhas da Carapa guianensis Aubl. e identificar suas respectivas funções.

\footnotetext{
${ }^{1}$ Engenharia Florestal, Universidade Rural da Amazônia, biachavees@gmail.com

${ }^{2}$ Engenharia Florestal, Universidade Rural da Amazônia, gabih-nascimento@outlook.com

${ }^{3}$ Engenharia Florestal, Universidade Rural da Amazônia, juniorefrcc.dj@gmail.com

${ }^{4}$ Engenharia Florestal, Universidade Rural da Amazônia, thgpantoja@gmail.com

${ }^{5}$ Mestranda em Ciências Arárias, Universidade Federal Rural da Amazômia, joypaananda_eng@gmail.com
} 


\section{Fundamentação Teórica}

Sabendo-se que a espécie possui um nível elevado quando se diz respeito à utilização no uso popular medicinal, através de saberes tradicional, resolve-se averiguar as folhas destas, já que não possui literaturas que façam apontamentos das características que podem ser utilizadas.

\section{Metodologia}

O estudo ocorreu no Laboratório Aplicado de Botânica da Universidade Federal Rural da Amazônia, no qual foi realizado a análise anatômica da espécie Carapa guianensis Abul, e identificadas as estruturas e características celulares que a espécie apresenta através de cortes transversais, longitudinais e paradérmicos da folha.

As amostras utilizadas no estudo, que consistem em galhos jovens, foram obtidas na área do Instituto de Ciências Agrária (ICA), coletadas de uma árvore com aproximadamente 8m de altura, por meio de um podador de $3 \mathrm{~m}$ de altura, no mês de março e realizadas a caracterização morfologia das folhas, frutos e sementes.

Para a análise microscópica do material botânico foram realizados cortes histológicos, os quais foram feitos a mão livre utilizando lâminas afiadas e colocados em placas de petri contendo água e em seguida, transferidos com a ajuda de um pincel de número zero, para lâminas devidamente identificadas, adicionou-se nas lâminas contendo os cortes da nervura central e face adaxial da folha, os corantes safranina e azul de astra respectivamente, e coberto com a lamínula. Finalizando os procedimentos de preparação das lâminas, as mesmas foram para análise no microscópio da marca OLYMPUS, onde capturaram as imagens por câmera fotográfica.

\section{Resultados e Discussões}

Na caracterização morfológica da folha, com auxílio da chave identificadora, foi observado que as folhas são compostas, pinada com disposição alterna e paripinada com a presença de pulvino na base da folha (figura 1).

A flor é pequena, unisexual, sésseis ou sub-sésseis, glabras, sub-globosas de cor branca a creme, sua inflorescência sustentadas por brácteas pontudas, axilar ou sub-terminal e seu fruto de cápsula globosa e sub-globosa com 4-6 valvas.

Figura 2. Pulvino da folha Carapa guianensis. Fonte: Própia. 


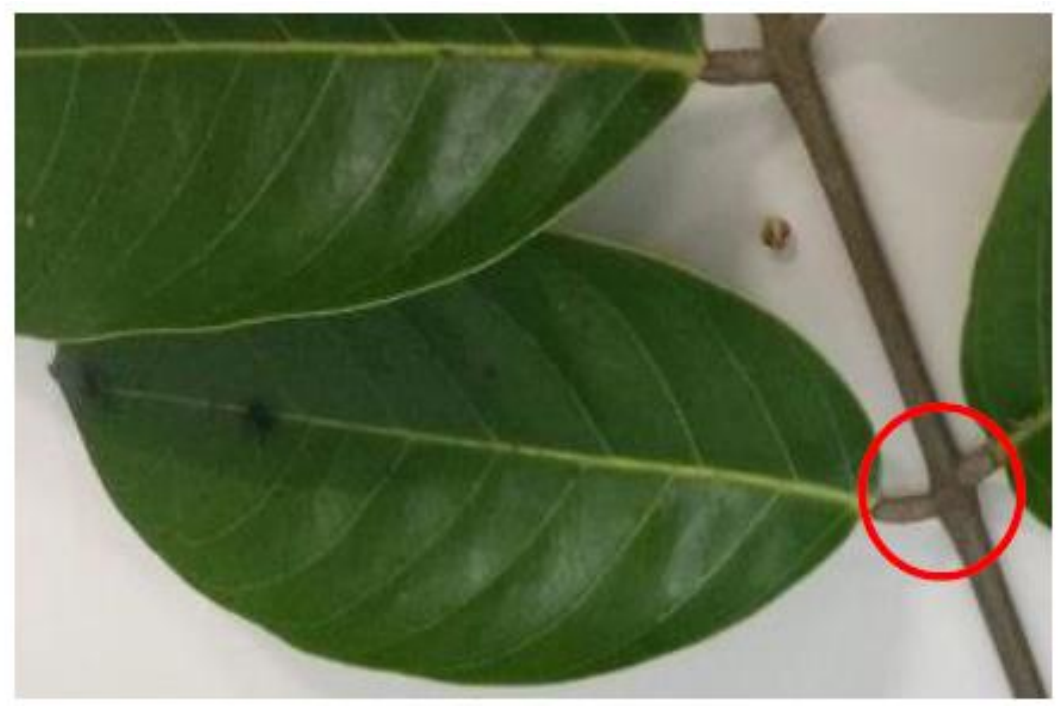

Na secção transversal, nota-se um mesófilo foliar, com epiderme superior e inferior, assimétrico, apresentando apenas uma carreira feixes de parênquima paliçádico e uma de lacunoso, foi possível visualizar uma estrutura secretora, que pode ser vulgarmente chamada de bolsões de óleo, observados na figura 2 , onde está destacado também com círculo em vermelho as células do floema, coradas com azul e as células do xilema, corados em vermelho.

Figura 2. Corte transversal na nervura central e mesofilo na folha de Carapa guianensis. Fonte: própia.

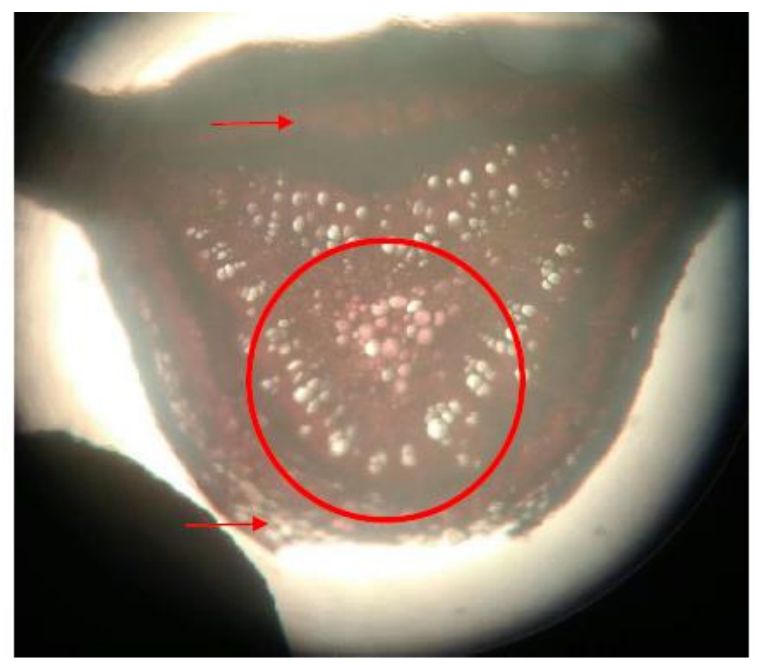

Foram identificados também fibras de esclerênquima, que são tecidos de sustentação e alguns canais próximos à epiderme. Foi possível verificar claramente estrutura secretora no corte longitudinal (figura 3), denominada de cavidade secretora, especificamente um ducto, que de acordo com Fahn (1979), é uma estrutura constituída por um epitélio secretor que delimita um espaço intercelular alongado. Nos cortes paradérmicos, tanto abaxial como adaxial (Figuras 4), nota-se a presença de estómatos e células do 
parênquima.

Figura 3. Corte longitudinal da dolha de Carapa guianensis. Fonte: Própia.

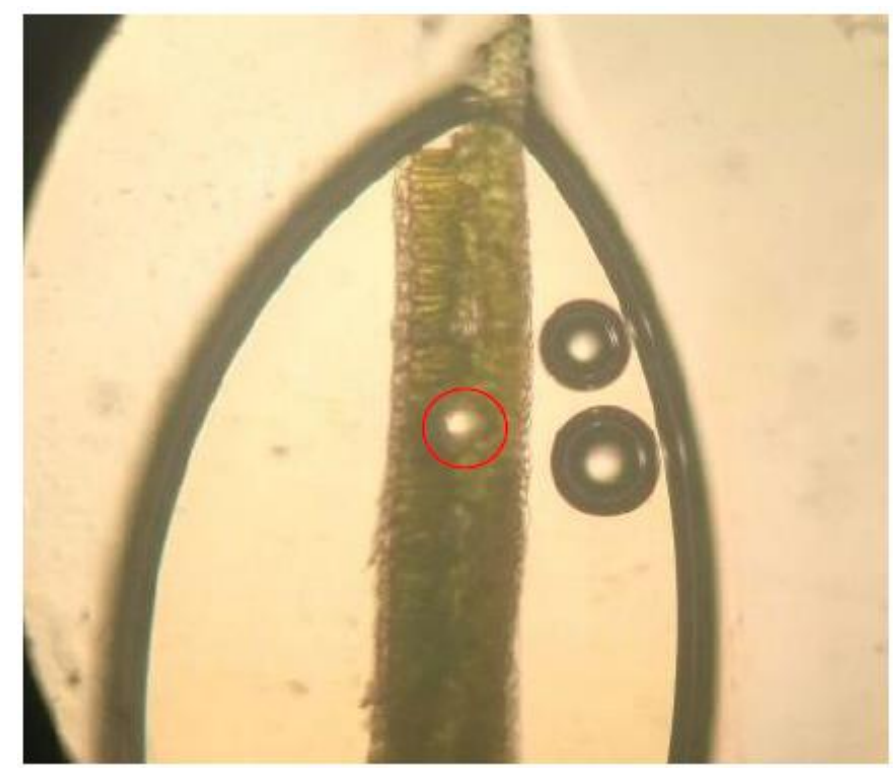

Figura 4. À esquerda corte adaxial e direita abaxial. Fonte: Própia.

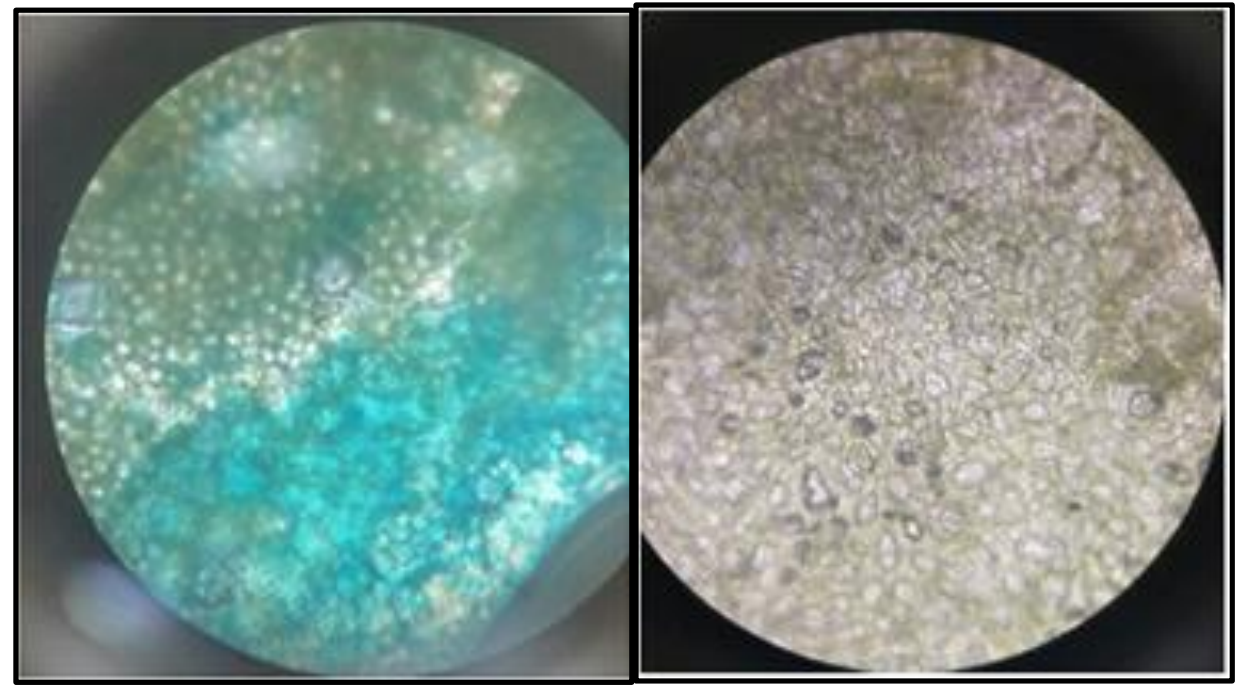

Das estruturas encontradas nas folhas da Carapa guianensis, é possível extrair óleos como o diclorometano, que é um hidrocarboneto clorado, líquido, incolor e volátil, amplamente utilizado como solvente e extratos metanólicos e etanólicos. Os extratos encontrados nas folhas da Andiroba são diferentes dos extraídos das sementes, que são popularmente mais conhecidos, onde são obtidos extratos hexânico e clorofórmico, além do óleo fixo.

Contudo, sabe-se que existe uma grande variação no teor de metabólitos secundários encontrados nas diferentes partes de uma mesma planta, dentro da família Meliaceae, e além dos limonóides, outras 
classes de metabólitos (triterpenóides e esteróides, alcalóides, proteínas, fenóis e fitoesteróis) também podem estar presentes na família Meliaceae.

\section{Conclusões}

A espécie florestal Carapa guianensis Aubl pode ser confundida com a espécie Carapa prócera, por isto a importância de ser realizada a caracterização morfológica antes da caracterização anatômica e estudos sobre as estruturas secretoras de Carapa guianensis Aubl, que visam aprimorar e identificar as estruturas presentes nas folhas e suas respectivas funções, ainda são raras, sendo importantes no contexto ecológico/evolutivo sob o qual a espécie poderá ser submetida.

A andiroba é popularmente conhecida por suas multi-utilidades, principalmente no setor farmacêutico, intensificando a importância da realização de estudos sobre suas propriedades, não apenas das sementes, que já são amplamente utilizadas, mas de toda sua estrutura, como as raízes, a madeira, o cipó, a casca, o córtex, o cerne, os galhos, as folhas e as flores, e o presente trabalho confirma as propriedades obtidas nas folhas para usos medicinais.

\section{Referências}

CARDOSO, P, R.; Estruturas secretoras em plantas. Instituto de botânica - IBt Programa de Pós Graduação em Biodiversidade Vegetal e Meio Ambiente Estágio de Docência CAPES. São Paulo, outubro de 2011.

COSTA, J, R,; MORAIS,R,R.; Carapa guianensis Abul., em Sistemas Florestais. Embrapa Amazônia Oriental, Manaus, AM, 2013.

CRONQUIST, A., 1988, The evolution and classification of flowering plants., Printed by Allen Press, Inc., 555p.

LORENZI, H. Árvores brasileiras: Manual de identificação e cultivo de plantas arbóreas nativas do Brasil. v.1, 3ª ed. Nova Odessa. Editora Plantarum, 265p, 2000.

Ministério da Saúde. MONOGRAFIA DA ESPÉCIE Carapa guianensis Aubl. (ANDIROBA). Ação $20 K 5$ (DAF/ SCTIE/ MS)/2012. Brasília, 2015.

NEVES, O, S, C.; BENEDITO, D, S.; Crescimento, produção de matéria seca e acúmulo de n, p, k, ca, mg e s na parte aérea de mudas de andiroba (carapa guianensis aubl.) KLEIN, R, M., Meliáceas. In: R. Reitz (ed.), Flora Ilustrada Catarinense,I Parte. R. Reitz ed. Itajaí, 1984. 